\title{
PARALLELS OF ALIENATION AND INDUSTRIAL PSYCHOLOGY: A CRITICAL ANALYSIS
}

\author{
Dilshan Lakshitha Fernando \\ Department of Human Resource Management \\ University of Kelaniya, Sri Lanka
}

\begin{abstract}
The rapidly growing global market conditions and the corresponding expansion of various market and economic variables and the global stage dramas played by various world powers to accumulate capital and establish their economic control over other countries (i.e. economic imperialism) and widening growth of the income disparity of the developing world, sets a perfect platform to initiate a broad discussion about the "human factor" which works in industries who generate the necessary capital to make countries rich and poor. When some selected businesses get richer and richer marginalised workers continuously are confronted with the grave issue of Alienation. It is the author's contention here to highlight the inadequacy of Industrial Psychology, the capitalist framework designed to deal with Alienation through a comprehensive discussion of Marxist principles and Industrial Psychology-proper. The paper will argue showing the evolution of Industrial Psychology as a distinct academic discipline that the persisting problem of alienation will continue to exist until political solutions are provided for wider class issues.
\end{abstract}

Keywords: Industrial Psychology, Alienation, Human Factor, Capital

\section{Introduction}

When some selected businesses get richer and richer marginalised workers continuously are confronted with the grave issue of Alienation. It is not my objective to evaluate the working conditions and the plight of the workers in the industries but rather to introduce a comparatively new texture of critique to industrial psychology and industrial based counselling which is a rare occurrence in the Sri Lankan context. Since my frame of discussion is within the limits of industrial psychology and counselling, I would hereby forward a critique to the traditional theories of industrial psychology and counselling by using classical and contemporary Marxist theories and concepts. I propose to criticise the subjects of industrial psychology and counselling through essential Marxist concepts of Alienation, Depersonalization, Reification and Class consciousness.

My critique would open doors for further discussion and debate in the subject matter and would present a highly philosophical, more insightful picture of the subject matter. Although a Marxist critique of this nature to industrial psychology and counselling is not a very novel idea or a brand new tradition, it is my contention 
that this is a new avenue introduced to the Sri Lankan academic discourse on industrial psychology and counselling. It must be further stated that it is pathetic to understand that there are hardly any critical debates on the subject matter in this country, after comprehending the essential importance of the aforesaid subjects in the human civilization.

To initiate the discourse, it is much more appreciate to lay down few formidable and accepted definitions for both industrial psychology and counselling to illustrate conceptually their essential link in my supposed critique.

\section{What is Industrial Psychology and} Counseling?

Counseling: Counseling is a process in which the counselor, or therapist, helps you understand the causes for your problems and guides you through the process of learning to make good life decisions.

Industrial Psychology: “.....to acquire better understanding and control of these relationships: ...between the worker and his work, worker and his immediate supervisor, between worker and management [and] between the worker and his fellow workers"

-Viteles (1933)-

Therefore it should be understood from the above two definitions that there is an essential unbreakable link between Industrial Psychology and Counselling. It is like they are two sides of the same coin.
Industrial Psychology introduces the principles for the maintenance of proper psychic levels of all the employees to achieve the company goals while Counselling serves in dealing with practical industrial disputes in the workplace due to the lack of the aforesaid correct psychology of the employee by identifying and proposing creative solutions to persistently carry on the smooth functioning of the organization without inappropriate breakages due to these employee disputes and psychological issues.

Therefore when dealing with either of the two subjects, the remaining one also should be taken into account deeply. That is why I brought forward theories from Industrial psychology to deal with Counselling issues in the work place.

\section{Historical Development of Industrial Psychology and Counselling}

With the onset of industrial revolutions in Great Britain and the United States of America during the late eighteenth and nineteenth centuries, respectively, the production process became increasingly specialised in nature (Carrell \& Heavrin, 1991). The artisan as master craftsman was being replaced by the unskilled labourer who could be trained with relative ease to perform the mostly simple and redundant work of the industrial factory or shop. This early deskilling of the production process introduced new opportunities for the exploitation of human labour as the increased control wielded by the owners of capital over the labour process enabled them to efficiently maximize returns on purchased labour time. 
Taylor And Scientific Management

A pioneer in the endeavour to streamline the production process and make the most efficient use of human labour was Frederick Taylor (1856-1915) whose research into the scientific management of the production process lay the ground work for the modern factory system of production (De Silva W. P., 1978). Taylor began his research towards the end of the 19th century using as working hypothesis for his studies the existence of a neoclassical style relationship between the owners of capital and the workers in which both attempt to maximize the returns on their labour investment, the former concerned with the maximization of profit, the latter with expending as little physical effort as possible for a given amount of pay (Viteless 1933, p.10)

Taylor's belief in the intellectual inferiority of the manual labourer led him to insist that the best interests of the worker could only be served through the expertise of the scientific manager who could guard against unnecessary physical exertion by formulating the most efficient application of human labour to productive capital. At the same time, he believed the best interest of business would be served due to increase in worker productivity made possible through the scientific management of work. Taylor's vision of the social implications of the scientific study of work was utopian; he envisioned a world in which productivity could be vastly increased to the benefit of all. In addition, he believed his scientific management principles held the potential for ".....the employers and the workmen who adopt it...the elimination of almost all forces for dispute and disagreement between them" (1911, pp.142143)

The influence of Taylor's scientific management principles on the development of industrial psychology was two-fold: first, its scope as a psychological speciality was clarifies by his micro level economic observations, and second, Taylor had to establish in the new field the primacy of the interests of the capital owners over the secondary or tertiary interest of the working class (Viteless, 1933, p.17)

\section{Early Industrial Psychologists}

\section{Hugo Musterberg}

An outline of his theories appeared in his 1913 book, 'Psychology and industrial efficiency' a product of the prestigious Leipzig laboratory, Musterberg was an excellent researcher and a methodologist, and expanded on Taylor's research in the field to include a wide variety of occupations. His research gave impetus to the growth of industrial psychology as serious scientific endeavour in Europe (Barret, Rhodes, \& Beishon, 1975).

Musterberg outline early in the evolution of industrial psychology goals to be worked towards and the interest that Ire to be served by the new field, stating unequivocally that the selection of those workers most beneficial to the capitalist enterprise, endeavouring increase per worker productive output, and the adjustment of the workers behaviour "in the interest of commerce and industry" Ire to be the primary aims of industrial psychology. (Braverman 1974, p.143) 


\section{$\underline{\text { Walter Dill Scott }}$}

Industrial psychology was popularized in the United State in large parts due to the efforts of Walter Dill Scott, a psychologist and a professor of North Western University. An earlier career in advertising led to Scott's interest in the psychology of work. Although not as influential as Musterberg, Scott pioneered the first treatise on the psychological principles of increasing the quantity and quality of labour output in his 1911 book, "Influencing men in business" (Mowday, Steers, \& Poter, 1982). Scott eventually became the first chair of the applied psychology at the Carnegie Institute of Technology where he continued his research his, like Musterberg, applied his finding in part towards maximising labour efficiency in the armed forces (Braverman, 1968, pp. 143-144)

\section{The Hawthorne Studies}

What Loren Baritz (1960, p. 77) has termed "the single most important social science research project ever conducted in industry" was performed in Chicago at the Western Electric Company's Hawthorne works during the years 1924 through 1933. Researchers from such prestigious bodies as the National research council, Massachusetts Institute of Technology and Harvard business school Ire involved with a series of methodologically rigorous experiments encompassing a wide range of variable thought to influence the efficiency of human labour (Manuel). Because of the exhaustive nature of the Hawthorne experiments, and the considerable expenditure of time necessary for their completion, the results of these studies Ire regarded as an authoritative guide to the type of service to be performed by the industrial psychologist.

Bramel and Friend 1981 believes those researchers involved in the Hawthorne experiments and particularly the Elton Mayo research, Ire instrumental in perpetuating an anti-worker pro-capitalist theoretical framework for industrial psychology.

\section{Alienation}

The term alienation originates from the work of Karl Marx on the effects on workers of the capitalist labour process and is Ill described in a number of studies (Adler, 2010). To Marx, alienation is a condition in which man becomes isolated and cut off from the product of his work, having given up his desire for selfexpression and control over his own fate at work. He finds that he enacts a role in which he is estranged from the kind of life of which he is capable (Fitzpatrick, 2006).

The genesis of this phenomenon can be traced to changes wrought by industrialisation, with the creation of large factories, characterised by organisational hierarchies, job specialisation and new patterns of work supervision and a shift in life focus away from the home and community to the organisation. These large factories needed an influx of considerable sums of capital for their construction, equipping them with machines and then to purchase the labour. By contrast, before the factory system work processes Ire not characterised by an extensive division of labour or coercive hierarchical authority (Manuel). 
The technical term for all this is known as the 'labour process'. The term labour process may sound complicated but the essential ingredients are easy to understand. It is the process through which labour power (work) is transformed into labour (product). In simple terms, workers (employees) produce a commodity that can be sold in the marketplace. It is the task of capital (employers) to so organise labour that a profit can be made. Inherent with this task is the control of all aspects of the process, such as holding down costs, increasing the use of machines (for example, automation and job deskilling) and organising work for efficiency. A consequence of this new form of factory work reduced the freedom and autonomy of workers to complete tasks as they saw fit. An important aspect of Marx is his concept of dialectic, the doctrine of opposites, referring to the struggle between opposing forces for control. $\mathrm{He}$ tried to explain history in terms of a struggle in which change takes place as a result of a dialectic: a dominant force (thesis) develops an opposition (antithesis) and a conflict ensues which is resolved by an outcome (synthesis) of what is of most value in each. Historically, for example, kings and slaves synthesised into feudalism, lords and serfs into capitalism, and now the dialectic between employers and employees. Therefore employees, for their part, seek to pursue their own interests such as job security, higher rewards, more satisfying work and attempt to counter the aims of employers, especially relating to control, by engaging in certain activities such as restricting work output and organising themselves industrially in unions and occupational, including professional, associations.
According to Hyman (1975) (Schroeder), modern industrial relations, in fact, centres on the issue of control. Marx held the view that alienation is an intrinsic part of the labour process and therefore unavoidable. This is because in selling their labour power (work) employees relinquish the right to control their own labour (product). Thus for Marx employers, not workers, have discretion over how and when work should be undertaken. This subordination of workers to their employers makes the activity of work a dehumanising and degrading experience.

To quote Marx (cited by Fox 1974: 224):

[Under capitalism] all the means for developing production are transformed into means of domination over and exploitation of the producer; that they mutilate the worker into a fragment of a human being, degrade him to become a mere appurtenance, make his work such a torment that its essential meaning is destroyed.

As a result of this destructive relationship Marx said that workers experience at least three forms of alienation:

- Alienation from the product of their labour (dispossessed of what they produce, which is owned by the capitalist)

- Alienation from oneself (only find extrinsic meaning in work and are separated from their true selves)

- Alienation from others (the unique qualities of humankind are diminished and so workers are estranged from both their own humanity and others) (Adapted from Corlett, 1988 and Deery \& Plowman, 1991) 
Marx regarded alienation as an objective reality (i.e. imposed as an external force) under capitalism, rather than simply a subjective state of mind. Hence it matters not that people might report that they do not feel alienated, since it is an objective state of capitalism: subjectivity is not part of the analysis. People who do claim to be satisfied and fulfilled are therefore really only expressing what he termed 'false consciousness'.

\section{Existential Psychology and Alienation}

Existential psychology therefore provides an interesting framework for analysing the effects of work and organisations on the individual because it focuses on the estrangement from one's inner or 'true' self, thus blocking growth, self-actualisation and meaningful interpersonal relationships (Schroeder). The significant point about the existential view of alienation and work is the rupture between this inner self and the 'created' or artificial self, resulting from choice - insofar as this is possible, given capitalistic organisations - which frustrate selfrealisation.

Hence I see a range of dysfunctional psychological outcomes emerge as employees attempt to reconcile their inner and artificial selves. Among these are depersonalisation, self-estrangement and loss of personal identity (Mowday, Steers, \& Poter, 1982), which in turn can have debilitating consequences for the individual. Marx himself was aware of the denial of inner self when, in the context of the labour process, he remarks that man "must subordinate his will to it" (Marx, 1976: 284). Alienation and problems in connection with the individual's adjustment to the demands of work organisations is Ill recognised; as Hunt (1986: 21) observes in reviewing research since the 1950s, "In summary, the literature proposed that something was dramatically wrong in the individual-organisation relationship."

\section{Work Structures and Alienation}

Organisation science has been criticised for overlooking the issue of alienation, in some cases going back a number of years, "organization science ... does not adequately address the issue of organization alienation" (Frost, 1980: 502). In particular, Frost points out that the organisation "is a significant barrier that separates them [individuals] from their true natures" (1980: 501). Organisations themselves can therefore be a source of alienation. Cognition by the employee of separation from the inner self can in turn lead to a reduction in organisational attachment and a deterioration in the individual-organisation relationship.

Probably the most pervasive structure is the bureaucratic, characterised byjob specialisation, authority hierarchy, merit appointment, record keeping, rules and impersonality (Iber, 1947), a cumulative effect of which is depersonalisation. Impersonal administration may be more desirable than management by whim, by separating the bureaucratic person from the office held; however, it results in the individual feeling a loss of self or personal identity, so becoming a mere $\operatorname{cog}$ in a dehumanising machine, an outcome also noted by Sanders (1997). The stifling effect of bureaucracies has been long known about, as Adler (1999: 
36) remarks in respect of bureaucratic red tape, over-controlling bosses and apathetic employees, there is a need to "set free the creative energy of employees by attacking the bureaucratic features of the organization." (Walton \& Valentin, 2014) This is not to deny that bureaucratic structures, or assembly lines for that matter, have given much to the world by way of increased efficiency and productivity; but the fact remains that a large part of scholarly research is aimed at trying to redress the malfunctions of these structures in an effort to engage employees with organisational goals and overcome their alienating effect.

\section{Management and Alienation}

Since its appearance as a concept in management theory, exemplified in the 1950s with the work of Argyris, (1957) and Merton (1957), alienation has been variously linked to, even conflated with, a range of conditions such as: satisfaction at work (Korman \& Wittig-Berman 1981; Trist, 1977; Vecchio, 1980; Westley, 1979) cynicism, burnout and depersonalisation (Andersson, 1996; Lee \& Ashforth, 1993; Sanders, 1997), work stress and alcohol use (Frone, 1999), powerlessness and a lack of control (Kanungo, 1992) and emotional labour (Ashforth \& Humphrey, 1993). These are in turn often attributed to, for example, factors of mass production technologies (Blauner, 1964), petty tyrants (Ashforth, 1994), poor management (Flannery, 2004), oppressive work of one sort or another (Freeperson, 1991) or organisational leadership problems (Sarros, Tanewski, Winter $\&$ Santora, 2002). To focus on managers as a cause may be misleading, however, since they are in fact the agents of capitalist principals. Both Marx and agency theory (Eisenhardt, 1989) would regard managers as akin to puppets, merely carrying out the wishes of the owners. As such, managers and even professionals can experience alienation as do other workers (Greene, 1978; Korman \& Wittig-Berman, 1981; Lee \& Ashforth, 1993; Hunt, 1986).

It seems, therefore, that a key to unravelling the problem of organisational alienation lies in understanding the intrinsic relationship between the authentic or inner self and the nature of the labour process itself. Attempts to redesign work appear to have only met with partial success. Efforts to increase autonomy, participation and involvement in decisions, self managing teams and efforts generally to enrich jobs, have all been tried but with mixed outcomes. Programs such as the quality of work life movement of the 1970s and present strategies involved with high-performance work systems reveal conflicting evidence of their efficacy, see for example Claydon and Doyle (1996), Mullins (2005). A crucial issue is that of control - are these efforts really aimed at giving workers more control over their work situation, or are they best described as pseudo arrangements? A continuing issue stems from the fact that managers, especially at loIr levels, are often unwilling to relinquish control over subordinates. Hellriegel and Slocum (1978) report on a number of less obvious methods of control, including budgets, structure, policies, recruitment, training, reward/punishment systems and technology including computers.

Selection and training together with efforts to 
secure high commitment and culture change stand out as prime candidates. They can be best described as covert mechanisms of control. Rather than overt methods such as autocratic supervision and bureaucratic structures, they operate psychologically to convince individuals that their inner self is aligned with their work self. This is attempted at three levels: firstly by only selecting persons who appear to be compatible with the organisation, its goals, structural arrangements and methods of operating.

Secondly by exposing new appointees to a training regime that inculcates them with the organisation's philosophies and beliefs. More subtle, however, is the third level, which embraces culture change for high commitment. Here, strategies are directed to the construction or reconstruction of individuals so that they will commit to the organisation, that is to say, accept organisational values as their own and who define themselves in terms of the changing requirements of the organisation (Salaman, 2001: 193).

Organisational commitment refers to an employee's emotional attachment to, identification with and involvement in, a particular organisation (Mowday, Porter and Steers (1982). As such it is generally considered to represent an individual's attitude towards the organisation, which influences workplace behaviours such as turnover and performance in that highly committed employees are less likely to leave, will support organisational goals and work harder (Mowday et al, 1982; Brown, 1996; Matthew \& Zajac, 1990). As Legge (1995: 179) observes from the literature on commitment, "it is assumed that the intention is to develop a strong, unitary, corporate culture, whereby organisational members share a commitment to values, beliefs, taken-for-granted assumptions that direct or reinforce behavimys considered conducive to organisational success."

Building on this, the normative literature holds that the behavioural component of commitment as an attitude is linked to better performance and one way of achieving this is by way of culture management. Legge (1995) regards this as a shift from one of forced compliance to one of commitment, in the sense that employees identifying with the organisation's goals and so to organisational success. The way this is achieved is through influencing organisational culture.

There is, however, some debate between the managerial and social science views of culture (see Salaman, 2001; Buchanan \& Huczynski, 2004). Where the managerial view holds that culture is something that organisations have and so has an objective reality that managers can create and use; the social science view is that culture is merely a subjective reality and just $i s$, meaning that, although it can be studied, the notion that it can be managed or manipulated is rejected. At the same time, however, the latter view does not completely deny that leaders may have some influence, since they are also involved in interactions which help shape the organisation's culture. Having said this, there is little doubt that organisations exert considerable effort to influence, manage and change culture aimed at increasing organisational performance. 
In so doing, it is argued that in essence the aim is to create a perception for the individual of an alignment between the inner and organisational self.

The fact that these efforts are at best only partially successful (Legge, 1995; Salaman, 2001; Guest, 1990; Wood, 1989) bears out the point that, even if it is possible to influence culture, there are extreme difficulties in achieving the alignment mentioned. Extensive management research in areas of commitment, control and culture has therefore only met with limited success in terms of dealing with alienation. Indeed, Noon and Blyton (2002: 236) speak of various ways employees survive alienation: making out (their informal regulation of work), fiddling, joking, sabotage and escaping.

\section{Human Resource Management and Alienation}

The factors outlined above fit snugly with the thrust of human resource management (HRM) models over the past twenty years, (Beer et al, 1984: Fombrun, et al, 1984; Guest. 1989), which emphasise, inter alia, outcomes of commitment, performance and strategic integration. These models represented a new approach to managing employees and the term HRM gradually replaced that of personnel management. There followed debate as to the meaning of HRM, which has persisted over the years due to inherent ambiguities and contradictions (Storey, 2001: 5). This debate focussed on whether HRM should be seen as a system designed to develop employees (the 'soft' version) or, alternatively, to ensure full utilisation of employees (the 'hard' version) (Keenoy, 1990; Storey, 1992). Given the psychological consequences of alienation already described, particularly revolving around self-alienation, a major question is whether HRM can really satisfy the needs of both the organisation and individual employees. Under the HRM model outcomes are equally beneficial for the organisation and all individual employees.

Within the present context HRM is also of interest due to its unitarist perspective and emphasis upon a culture of commitment. Under unitarism, conflict is de-emphasised (Storey, 18 1992) to the point where it is attributed either to troublemakers or unwanted third parties interfering with the employer-employee relationship. Within the unitarist HRM model genuine conflict is not possible because there is a conjunction of interests between employer and employee. The other significant characteristic of the unitarist HRM model is the strategic link between top management and practising HR managers. Here, HRM with its emphasis on a culture of commitment is the vehicle for achieving management's goals, so that there is little scope for HR managers to represent the needs of workers. Indeed, in most cases day-today HR functions are delegated to line managers, releasing HR managers to concentrate on strategy (Purcell, 2001).

Notionally, at least, HRM with its unitarist underpinnings could have provided a solution to problems of organisational alienation and estrangement. It idealistically saw the natural state of employer-employee relations as one of 
agreement in which there was a confluence of interests. Clearly, this would have represented a return to situations in which employees no longer suffered feelings of isolation and could experience self-expression and control over their work. However, the claims of HRM proponents that it can engineer such outcomes, together with its flawed unitarist assumptions, have been questioned and criticised for a number of years (Guest \& Hoque, 1994; Legge, 1995; Guest, 1999; Sisson, 2001; Storey, 2001). Legge (2001), for example, examines the evidence that culture management can deliver the double benefits of commitment and high performance, but finds that there are serious doubts about the validity of research that purports to demonstrate such a linkage. In particular she notes the lack of longitudinal data that might support the HRM-performance linkage. Guest (2001: 111) observes that, "One of the important and persistent findings from research is the low adoption of 'high commitment' or progressive human resource practices" and in doing so casts doubt on the efficacy of HRM. The questions raised earlier about the problematic issue of whether it is possible to change organisational culture - taking the managerial view - remain unanswered. A further matter concerns the much lauded swing away from collectivism to individualism under HRM (Purcell, 1987; Storey \& Bacon, 1993). Whilst this shift might suit employers for a variety of reasons such as de-unionisation and the striking of individual agreements, contrary to the rhetoric it arguably serves only to reinforce the manager's power and control; it hardly fits with notions of joint consultation and stimulating identification with organisational culture.
Two approaches that may offer a solution to the problems of alienation, can be found in remnants of past practices but which have not been fully exploited. Firstly, HRM may be contrasted with the tenets of personnel management, which it is considered to have replaced.

Where, formerly, personnel management recognised pluralist values and goals, and saw negotiation as a method of resolving conflict, HRM's unitarist position regards conflict as an aberration from the norm. In practice, personnel managers Ire able to use their negotiating skills in resolving problems between line managers and employees. As such, workers regarded them as an in-house 'umpire' who would treat their complaints both fairly and dispassionately. The old pluralist-based personnel management is therefore an approach that could be employed to recognise the individual's inner or 'true' self. Taken beyond the need to resolve conflict in the workplace, HRM could also tailor work to the individual. This is, of course, a return to one of the central themes of ergonomics, but this time around could be specifically directed to matching work to the true inner self.

Secondly, and following on from this point, more could be done to vocationally match individuals to work, Although directive vocational guidance has been discarded in favour of individual choices in selecting work, such an approach makes enormous assumptions about the ability of potential employees to make meaningful decisions. This means going beyond merely assessing skills and aptitudes, to investigating the underlying psychological makeup of the inner or 'true' self. The present 
focus on job 'interests' rather than job 'fit' may Ill

need to be modified. This in turn demands additional work in the area of personality testing and employment selection which, as already implied, appears to stop at assessing skills and abilities.

\section{Conclusion}

Industrial Psychology and Counselling is just an ideological artefact. It is merely an ideology in the classical Marxist sense and is a historically essential development of late Capitalism.

It has been argued in this paper that worker alienation is a much-neglected issue, particularly in respect of the effect it has on producing feelings of powerlessness, isolation and loss of self-identity. The importance of these feelings to Ill-being at work can be traced to Marx and existential psychology, the central feature of which is estrangement from one's inner or true self. Various management ploys, intended to provide long-term solutions, have largely been unsuccessful. The HRM model appeared at first to provide some hope of alleviating the symptoms. However, rather than helping to overcome these feelings,

HRM and counselling seems to exacerbate the problem by leaving social needs unmet through its emphasis on individualism and making unitary assumptions about the goals and interests of employers and workers. This seems particularly at odds in pluralistic societies and the current emphasis in management circles on diversity.
HRM, Industrial Psychology and Counselling is flawed because it cannot deal with alienation. It attempts to subvert workers from their inner or true selves by overt or covert means, particularly through seeking to establish a culture of commitment. But the classic problems of alienation refuse to go away because the nature of the employer - employee relationship is such that no amount of benign HRM can fundamentally alter. This is not to deny that HRM seeks to achieve outcomes that would bring with it individual Ill-being, organisational effectiveness and societal Ill-being (Beer et al 1984). However, the point remains that the unitarist HRM model has serious shortcomings in helping to overcome feelings of alienation; indeed, it appears probable that feelings of alienation may be exacerbated due to the dysfunctional consequences of Industrial Psychology and Counselling.

A more productive approach to dealing with alienation appears to be to invest more in selection processes that emphasise matching work to the inner or 'true' self and by fitting the work to the psychological makeup and personalities of job applicants.

\section{References}

Adikaram, A. S. (2008). Labour Law and Relations: A human resource management approach. Sri Lanka: Stamford Lake.

Adler, P. S. (2010). Marxist Philosophy and organizational studies: Marxist contributions to the understanding of some important organizational forms. In Research in the Sociology for Organisations. 
Armstrong, M. (2012). Armstrong's Handbook of Human Resource Management Practice. London, Philadelphia and New Delhi: Kogan Page Ltd.

Barret, B., Rhodes, E., \& Beishon, J. (1975). Industrial Relations and the Wider Society. London: Collier Macmillan London Ltd.

Carrell, M. R., \& Heavrin, C. (1991). Collective Bargaining and Labour Relations. New York: Macmillan Publishing Company.

De Silva, S. (1996). Collective Bargaining Negitiations. International Labour Organization.

De Silva, S. (2004). The transformation of labour law and relations. Sri Lanka: Stamford Lake.

De Silva, W. P. (1978). Industrial Conflict. Colombo: Lake House Investments Ltd.

Dhammika, K. A., Ahmed, F. B., \& Sam, T. L. Managerial Perception about Unionization and its effect in Sri Lankan Public Sector Organizations.

Edralin, D. M. (1999). Collective bargaining process and its outcomes. CBE Working Paper Series .

Fitzpatrick, K. D. (2006). Effective Grievance Handling. Labor Management Conference. Georgia.

Gamage, P. N. (n.d.). Mutiplicity of Trade Unions in Sri Lanka: Challenges and Issues in Sri Lankan Perspective.
Gamage, P. N., \& Hewagama, G. V. (2007). An Empirical Study of Grievance Settlement and Labour Management Relationship in Apparel Industry of Sri Lanka. Kelaniya Journal of Human Resource Management , 2 (2), 170-186.

Gamage, P. N., \& Hewagama, G. V. (2008). An empirical study of Grievance Settlement and Labour Relationship in Apparel Industry of Sri Lanka. 4th International Conference on Management. Gain Jyothi Institute of Management \& Technology, Panjab Technical University Chandigar, India.

Gamage, P. N., \& Hewagama, G. V. (2011). Union leadership and Member Attitudes in determining Union Participation: Evidence from Public Sector of Sri Lanka. International Research Conference on Management \& Finance. University of Colombo.

Kearney, R. N. (1971). Trade Unions and Politics in Ceylon. California: The Regents of the University of California.

Kim, J.-W., \& Rowley, C. (2011). Commitment to company and labour union: empirical evidence from South Korea. The International Journal of Human Resource Management , 673-692.

Lee, J. (2007). Company and union commitment: evidence from an adversarial industrial relations climate at a Korean auto plant. The International Journal of Human Resource Management, 1463-1480.

Manuel, A. L. The Concept of Alienation in Marx. College of Public Administration, University of Philippines. 
McGregor, D. (1960). The Human Side of Enterprise. New York: McGrawHill.

Messer, I. (1975). Marx's Theory of Alienation.

Mowday, R. T., Steers, R., \& Poter, L. (1982). The psychology of commitment, absenteeism and turnover. New York.

Opatha, H. D. Manegerial attitudes towards labour unions: some suggestions. Human Resource Management , I (Paper 08), 6469.

Opatha, H. H. (2012). Human Resource Management. Nugegoda: University of Sri Jayawardenepura.
Palmer, S. (1997). Handbook of Counseling. Prosci. (2014). Reinforcing change with employee feedback. Retrieved from Prosci: http://www.change-management.com/ tutorial-reinforcing-mod1.htm

Rajaratnam, T. W. (1992). A Manual of Labour Law. Colombo: Colombo Catholic Press.

Schroeder, T. Explaining Organizational Citizenship Behavior: A Critical Review of the Social Exchange Perspective.

Walton, J., \& Valentin, C. (2014). Human Resource Development: Practices and Orthodoxies. New York: Palgrave Macmillan.

Williams, A. H. (2002). How to Discipline and Document Employee Behaviour. Tennessee: M. Lee Smith Publishers LLC. 